\title{
Notch ligand, JAG1, is evolutionarily conserved target of canonical WNT signaling pathway in progenitor cells
}

\author{
MASUKO KATOH $^{1}$ and MASARU KATOH ${ }^{2}$ \\ ${ }^{1}$ M\&M Medical BioInformatics, Hongo 113-0033; ${ }^{2}$ Genetics and Cell Biology Section, \\ National Cancer Center Research Institute, Tokyo 104-0045, Japan
}

Received December 12, 2005; Accepted January 20, 2006

\begin{abstract}
WNT, Notch, FGF, and Hedgehog signaling pathways network together during embryogenesis, tissue regeneration, and carcinogenesis. Association of Notch ligands with Notch receptors on neighboring cells leads to cleavage of Notch receptors by metalloprotease and $\gamma$-secretase to induce nuclear translocation of Notch intracellular domain (NICD). Nuclear complex, consisting of CSL (RBPSUH), NICD, Mastermind (MAML), p300 and histone acetyltransferase (HAT), then induces transcriptional activation of Notch target genes, such as HES1, HES5, HES7, HEY1, HEY2 and HEYL. Here, we searched for TCF/LEF-binding site within the promoter region of Notch ligand genes, including $D L L 1$, DLL3, DLL4, JAG1 and JAG2. Because TCF/LEF-binding sites were identified within human $J A G 1$ promoter based on bioinformatics and human intelligence, comparative genomics analyses on JAGl orthologs were further performed. Chimpanzee JAG1 gene, consisting of 26 exons, was identified within NW_120319.1 genome sequence. XM_525264.1 and XM_514517.1 were not the correct coding sequences for chimpanzee JAG1. Chimpanzee JAG1 gene was found to encode a 1218-amino-acid protein showing $99.5 \%$ and $96.2 \%$ total-amino-acid identity with human JAG1 and mouse Jag1, respectively. Phylogenetic analysis revealed that JAG1 orthologs were more conserved than those of other Notch ligands. JAG1 gene was identified as evolutionarily conserved target of WNT/B-catenin signaling pathway based on the conservation of double TCF/LEF-binding sites within 5 '-promoter region of mammalian JAG1 orthologs. Human $J A G 1$ mRNA was expressed in embryonic stem (ES) cells, neural tissues, lung carcinoid, gastric cancer, pancreatic cancer, colon cancer, and also in squamous cell carcinoma (SCC) of skin, oral cavity, esophagus, head and neck. JAG1 expression on progenitor cells due to canonical WNT signaling activation
\end{abstract}

Correspondence to: Dr Masaru Katoh, Genetics and Cell Biology Section, National Cancer Center Research Institute, 5-1-1 Tsukiji, Chuo-ku, Tokyo 104-0045, Japan

E-mail: mkatoh@ncc.go.jp

Key words: bioinformatics, comparative genomics, comparative proteomics, WNT, NOTCH, integrome network induces self-renewal of stem cells due to Notch signaling activation. JAG1, functioning as WNT-dependent Notch signaling activator, is the key molecule maintaining the homeostasis of stem and progenitor cells.

\section{Introduction}

WNT, Notch, FGF, Hedgehog, and BMP signaling pathways network together during embryogenesis, tissue regeneration, and carcinogenesis (1-24). Because Wnt1, Wnt3, Wnt10b, Notch4, Fgf3, Fgf4 and Fgf8 are up-regulated during mouse mammary carcinogenesis due to MMTV integration, WNT, Notch ligand, and FGF are predicted as key regulators of stem and progenitor cells.

Notch signaling pathway is implicated in the maintenance of self-renewal potential in stem cells, binary cell-fate determination in progenitor cells, and induction of terminal differentiation in proliferating cells $(9,10)$. Delta homologs (DLL1, DLL3, DLL4) and Serrate homologs (JAG1, JAG2) are transmembrane-type ligands for Notch family receptors, including NOTCH1, NOTCH2, NOTCH3 and NOTCH4 (25-33). Association of Notch ligands with Notch receptors on the neighboring cells leads to the cleavage of Notch receptors by metalloprotease and $\gamma$-secretase to induce nuclear translocation of Notch intracellular domain (NICD). Nuclear complex, consisting of CSL (RBPSUH), NICD, Mastermind (MAML), p300 and histone acetyltransferase (HAT), then induces transcriptional activation of Notch target genes, such as HES1, HES5, HES7, HEY1, HEY2 and HEYL. Because HES/HEY family members are bHLH-type transcriptional repressors, Notch signaling activation in stem cells leads to the maintenance of self-renewal potential through the downregulation of tissue-specific transcription factors (9,10,34-36).

Here, we searched for TCF/LEF-binding site within the promoter region of Notch ligand genes, including $D L L 1$, DLL3, DLL4, JAG1 and JAG2. Because double TCF/LEFbinding sites were identified within human JAG1 promoter based on bioinformatics and human intelligence, comparative genomics analyses on JAG1 orthologs were further performed.

\section{Materials and methods}

WNT target gene screening. Genome sequences corresponding to human DLL1, DLL3, DLL4, JAG1 and JAG2 genes were searched for with BLAST programs (http://www.ncbi.nlm. 
A

\begin{tabular}{ccccc}
\hline $\begin{array}{c}\text { Human } \\
\text { gene }\end{array}$ & $\begin{array}{c}\text { Chromosomal } \\
\text { localization }\end{array}$ & RefSeq ID & $\begin{array}{c}\text { Genome } \\
\text { clone }\end{array}$ & $\begin{array}{c}\text { TCF/LEF- } \\
\text { binding sites }\end{array}$ \\
\hline DLL1 & $6 q 27$ & NM_005618.2 & AL078605.30 & \\
DLL3 & $19 q 13.2$ & NM_203486.1 & AC011500.7 & \\
DLL4 & $15 q 15.1$ & NM_019074.2 & AC020661.8 & Double sites \\
JAG1 & $20 p 12.2$ & NM_000214.1 & AL035456.26 & Do \\
JAG2 & $14 q 32.33$ & NM_002226.3 & AL512355.6 & \\
\hline
\end{tabular}

B

\begin{tabular}{|c|c|c|c|c|c|c|c|c|c|c|c|}
\hline $\begin{array}{c}\begin{array}{c}\text { Exon } \\
\text { No }\end{array} \\
\begin{array}{l}1 \\
2 \\
3\end{array}\end{array}$ & \multicolumn{3}{|c|}{$\begin{array}{l}\text { Nucleotide sequence around } \\
\text { exon - intron boundaries }\end{array}$} & $\begin{array}{c}\begin{array}{c}\text { Exon } \\
\text { No }\end{array} \\
10 \\
11 \\
12\end{array}$ & \multicolumn{3}{|c|}{$\begin{array}{l}\text { Nucleotide sequence around } \\
\text { exon - intron boundaries }\end{array}$} & $\begin{array}{c}\text { Exon } \\
\text { No }\end{array}$ & \multicolumn{3}{|c|}{$\begin{array}{l}\text { Nucleotide sequence around } \\
\text { exon - intron boundaries }\end{array}$} \\
\hline $\begin{array}{l}1 \\
2 \\
3 \\
4 \\
5 \\
6 \\
7 \\
8 \\
9 \\
9\end{array}$ & $\begin{array}{l}\text { eggcag } \\
\text { ttgcag } \\
\text { ctctag } \\
\text { ttacag } \\
\text { ctceag } \\
\text { tggeag } \\
\text { ttgcag } \\
\text { gaccag }\end{array}$ & 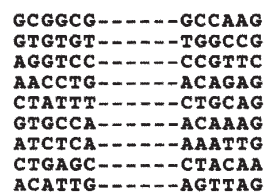 & $\begin{array}{l}\text { gtagga } \\
\text { gtgagt } \\
\text { gtaagt } \\
\text { gtatgt } \\
\text { gtaat } \\
\text { gtatgg } \\
\text { gtagagt } \\
\text { gtaagt } \\
\text { gtaaga }\end{array}$ & $\begin{array}{l}10 \\
11 \\
12 \\
13 \\
14 \\
15 \\
16 \\
17 \\
18\end{array}$ & $\begin{array}{l}\text { tttcag } \\
\text { ttttag } \\
\text { ttctag } \\
\text { ttgcag } \\
\text { ttctag } \\
\text { tcatag } \\
\text { ttctag } \\
\text { ctcog } \\
\text { ttatag }\end{array}$ & 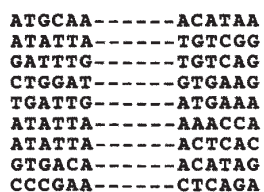 & $\begin{array}{l}\text { gtgagt } \\
\text { gtatgt } \\
\text { gtgagt } \\
\text { gtacet } \\
\text { gtaaga } \\
\text { gtgagt } \\
\text { gtaggt } \\
\text { gtaact } \\
\text { gtgagt }\end{array}$ & $\begin{array}{l}19 \\
20 \\
21 \\
22 \\
23 \\
24 \\
25 \\
26\end{array}$ & $\begin{array}{l}\text { ttgcag } \\
\text { tcttag } \\
\text { tcctag } \\
\text { tgtcag } \\
\text { ctcag } \\
\text { ttttag } \\
\text { ttccag } \\
\text { ttacag }\end{array}$ & 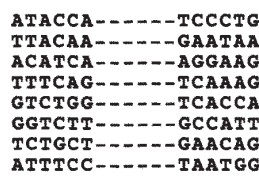 & $\begin{array}{l}\text { gtaagt } \\
\text { gtaagg } \\
\text { gtatgt } \\
\text { gtagga } \\
\text { gtatgt } \\
\text { gtagt } \\
\text { gtaggt }\end{array}$ \\
\hline
\end{tabular}

Figure 1. (A) Human Notch ligand family. DLL1, DLL3, DLLA, JAG1 and JAG2 genes constitute Notch ligand family. Double TCF/LEF-binding sites are located within the 5'-promoter region of $J A G 1$ gene. (B) Exon-intron structure of chimpanzee $J A G 1$ gene. Nucleotide sequences around exon-intron boundaries are shown by upper-case letters (exon) and by lower-case letters (intron). (C) Phylogenetic tree of human and mouse Notch ligands. JAG1 orthologs are more conserved than those of other Notch ligands.

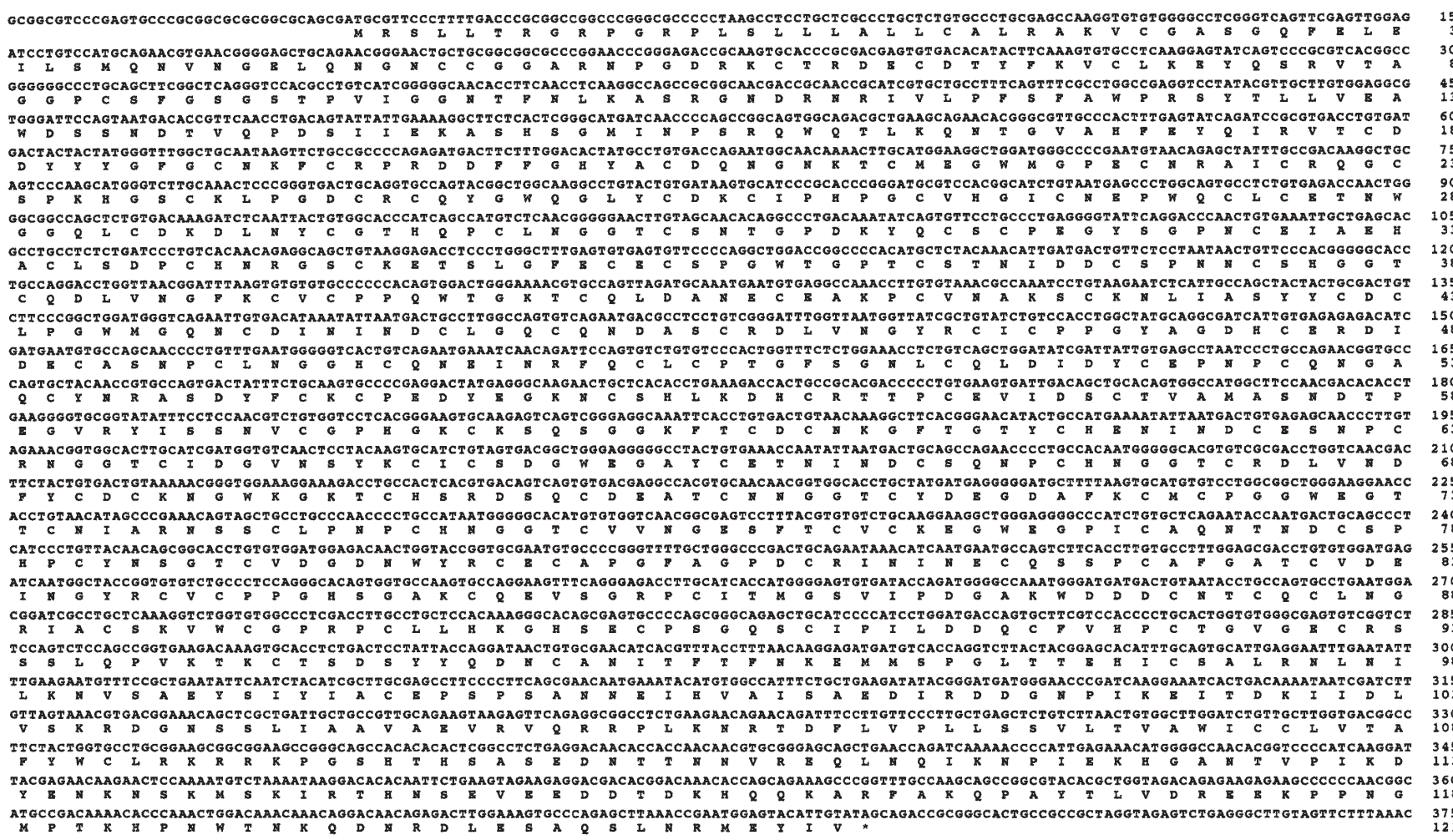

\section{38 ${ }_{88}^{300}$ 438 188 738 288

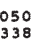 ${ }_{388}$ 4350 1500
488 2400
788 3600
1188
128} 1650
538 1800
588 1950
638 2100
688 ${ }_{738}^{2250}$ 788
2550
838 2700
888 $\stackrel{2850}{938}$ 938
3000
988 988
3150
1038 3300
1088 3450
1138 3750
1218

Figure 2. Nucleotide and amino-acid sequences of chimpanzee JAG1 complete CDS. Nucleotides and amino-acid residues are numbered on the right.

nih.gov) as described previously (37-39). TCF/LEF-binding sites within the 5'-flanking promoter region of above genes were searched for based on bioinformatics and human intelligence as described previously (40-42).

Identification of the chimpanzee JAG1 ortholog. Chimpanzee genome sequence homologous to human JAGl was searched for with BLAST programs as described previously (43-45). Exon-intron boundaries were determined by examining the consensus sequence of exon-intron junctions ('gt .... ag' rule of intronic sequence) and the codon usage within the coding region as described previously (46-48). Coding sequence of chimpanzee JAG1 was determined by assembling exonic regions. 


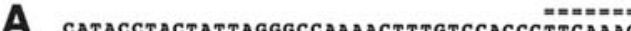

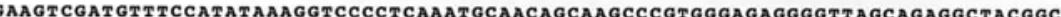
CAGCCCACGGGCTTTCTTCGACCTTGATTATGACCAGGAGTGTAGCTGTTAATTGCGAGGCTTGCCTCAAGGTGGAAACAGTATCGGTTCCACTGCCACCCCAGAGAAGCAAGTTCC GCGGCTGGCGGTGCTGGGACACGGTCCCTCCCAGGCCCATCTCTTGCCACCCAGAGAGTGCTCGGAGGCCGCCTACAGGTGCAATCCCGGCACTGCGGCCGGGCGTCGGGCCGGGA GGGCGTCCAAGCCCACCAGCATCTCCGCCGGCCCTTCCCAAAGCCTGAACAGGGCCCCGGCGTGCCCGCCGCCTTCTACCCCCGGTTCCCCGCGCCTCTGCCCCGGCGCGGTTTGGATA

GGAAGCTGGGAGCCCTCCCAGGCTCCGCAGACTCGGATTTGGGAGGGGTGGGACGCGGCCGAGGCTTCCCCTCGAATCTGCGGCAAGCCTGGCTCCAGGAAAGTTTTCAAAGTTCCCA GCAGCGTCTGCCCAGGTCGCCTCCGCGGGGCGAGCAGACGGCGGCAAGCGCGCCAGCCTCGCCGCCGCCTCTGCCGCCAGCAGAGCGCTCTOGGCGGCTCGCTCOCGGGAACGOCOCOA ACTCCCGGCGGGCAGGCAGGCCCTCCTCCCGGGGCGAAAGCCGCAGCTGACGCAGGCGGTTCGGAAGGCGGAAGCTGCCCCGCTCCGACCGCTCAGTCAGCGCCGCCGCGCCTACACCTO GGGCCCCGACGCGCGGGCAAAGCGCACGGCCCGGGGGCCCGAGGGGCGGTCCCCGCTGGGGGCTCCAGGCGTCCCTGAGCAACGATCCCTTCCAAGTACCTCCCCGCACTCTCCCE TCCCTCCTGGCCCGAGCTCCCGAGGCGGGGTTGTGTGGGCCCTGGTTCTTCTACGCCGCCCTGAGCATCCCGCTGCCCCCAACCCCTTCCAAGTTCCTCCTCGCACTACCCCCTC CCCAGCAACGTGAAGGGGAGGGCGTGCCCAGGGTGAGCACGCCCTCTCATGAATATTAATAAGCGCGCATGCGCCCTGCCCGGCGTGCTGGGTAGAGGTGGCCAGCCCCGGCCGCTGCT GCOAGACGGGTCTCCGGGTCTTCTCCGAGAGCGGGGGGCACGCGTCATTGTGTACCTGCGGCCGGCCGCGAGTAGGCTGGTTTTTTTTTCTCCCCTCCCTCCCCCCTTTT

B
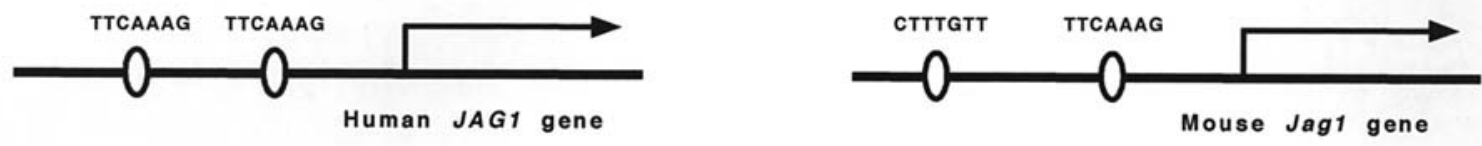

C
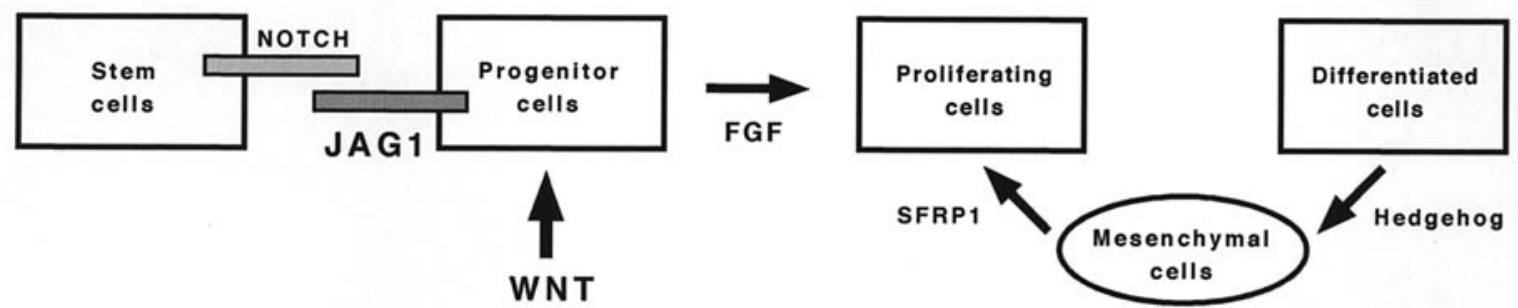

Figure 3. (A) Nucleotide sequence of human JAG1 promoter region. TCF/LEF-binding sites are shown by double over-lines. Region corresponding to exon 1 of human JAG1 gene is boxed. (B) Schematic representation of promoter regions of human JAG1 and mouse Jag1. Double TCF/LEF-binding sites are conserved between human JAG1 promoter and mouse Jag1 promoter. (C) WNT and Notch signaling networks for the homeostasis of stem and progenitor cells. Canonical WNT activates the WNT/ß-catenin signaling pathway to induce JAG1 expression in progenitor cells. JAG1 on progenitor cells then activates the Notch signaling pathway in stem cells to maintain self-renewal potential.

Comparative proteomics analysis. Phylogenetic analyses on mammalian Notch ligand family members were performed by using the CLUSTALW program.

Comparative genomics analyses. Promoter region of human and mouse JAGl orthologs were aligned by using the Genetyx program and manual curation. TCF/LEF-binding sites within the promoter region were determined as mentioned above.

In silico expression analysis. Expressed sequence tags (ESTs) derived from human $J A G 1$ gene were searched for by using the BLAST programs. The sources of JAG1 ESTs were listed up for in silico expression analysis on JAG1 mRNA.

\section{Results}

Screening of TCF/LEF-binding site within promoter region of Notch ligand genes. Human DLL1 RefSeq (NM_005618.2), DLL3 RefSeq (NM_203486.1), DLL4 RefSeq (NM_ 019074.2), JAG1 RefSeq (NM_000214.1) and JAG2 RefSeq (NM_002226.3) were used as query sequences for the BLAST programs to identify genome clones corresponding to Notch ligand family genes. The 5'-flanking promoter region of human DLL1, DLL3, DLL4, JAG1 and JAG2 genes were identified within AL078605.30, AC011500.7, AC020661.8, AL035456.26 and AL512355.6 genome sequences, respectively (Fig. 1A). TCF/LEF-binding sites within the 5'-promoter region of human DLL1, DLL3, DLLA, JAG1 and JAG2 genes were then searched for. Double TCF/LEF-binding sites were identified within human JAGl promoter based on bioinformatics and human intelligence (Fig. 1A).
Identification of the chimpanzee JAG1 gene. BLAST programs using human JAG1 RefSeq revealed that chimpanzee JAG1 gene was located within NW_120319.1 genome sequence. Exon-intron boundaries of chimpanzee JAG1 gene were determined based on the consensus sequence of exon-intron junctions. Chimpanzee JAG1 gene was found consisting of 26 exons (Fig. 1B).

Chimpanzee JAG1 predicted sequence XM_525264.1 corresponded to 5'-franking fragments, exons 2-4, 6-16 and introns of chimpanzee JAG1 gene. Another chimpanzee JAG1 predicted sequence XM_514517.1 corresponded to exons $17,18,20-26$ of chimpanzee JAGl gene. Because XM_525264.1 and XM_514517.1 were not the correct chimpanzee JAG1 sequences, complete coding sequence (CDS) of chimpanzee JAG1 was determined in this study by assembling nucleotide sequences of 26 exons (Fig. 2).

Genetyx program revealed that nucleotide position 37-3693 was the coding region of chimpanzee JAG1 complete CDS (Fig. 2). Chimpanzee JAGl gene was found to encode a 1218-amino-acid protein showing $99.5 \%$ and $96.2 \%$ totalamino-acid identity with human JAG1 and mouse Jag1, respectively.

Comparative proteomics analysis on mammalian Notch ligand family members. Phylogenetic analysis revealed that JAG1 orthologs were more conserved than other orthologs of Notch ligand family members (Fig. 1C).

Expression of human JAG1 mRNA. In silico expression analysis revealed that human JAG1 mRNA was expressed in embryonic stem (ES) cells, neural tissues, lung carcinoid, 
gastric cancer, pancreatic cancer, colon cancer, and also in squamous cell carcinoma (SCC) of skin, oral cavity, esophagus, as well as head and neck.

Comparative genomics analyses on JAG1 promoters. Human $J A G 1$ promoter and mouse Jagl promoter were located within AL035456.26 and AL713981.17 genome sequences, respectively. Because chimpanzee JAG1 promoter was located within the sequencing gap of NW_120319.1 genome sequence, 5 '-promoters of human and mouse JAGl orthologs were compared.

Double TCF/LEF-binding sites within human JAG1 promoter were located about $1200 \mathrm{bp}$ and $600 \mathrm{bp}$ upstream of the transcription start site (Fig. 3A). The region corresponding to about 1100 upstream of the transcription start site of human JAGl gene, including the proximal TCF/LEFbinding site, was well conserved in mouse (Fig. 3B). The distal TCF/LEF-binding site of human JAG1 promoter corresponded to inverted TCF/LEF-binding site about 1400 bp upstream of the transcription start site of the mouse Jagl gene (Fig. 3B). Therefore, double TCF/LEF-binding sites were conserved among the human JAGl and mouse Jagl promoters.

\section{Discussion}

TCF/LEF-binding site within the promoter region of genes encoding Notch ligands, including DLL1, DLL3, DLL4, $J A G 1$ and $J A G 2$, were searched for. Because double TCF/ LEF-binding sites were identified within human JAG1 promoter based on bioinformatics and human intelligence (Fig. 1A), comparative genomics analyses on JAG1 orthologs were further performed in this study.

Chimpanzee JAG1 gene, consisting of 26 exons, was identified within NW_120319.1 genome sequence (Fig. 1B). Because XM_525264.1 and XM_514517.1 were not the correct coding sequences for chimpanzee JAG1, complete CDS for chimpanzee JAG1 was determined by assembling nucleotide sequences of exonic regions (Fig. 2). Chimpanzee JAG1 gene was found to encode a 1218-amino-acid protein showing $99.5 \%$ total-amino-acid identity with human JAG1. Phylogenetic analyses revealed that JAG1 orthologs were more conserved than those of other Notch ligands (Fig. 1C).

$J A G 1$ gene was identified as evolutionarily conserved target of $\mathrm{WNT} / \mathrm{B}$-catenin signaling pathway based on the conservation of double TCF/LEF-binding sites within the 5'-promoter region (Fig. 3B). WNT/B-catenin signaling pathway is activated in progenitors cells (23). JAG1 is expressed on progenitor cells within the epithelium of adult gastointestinal tract (49). JAG1 is the ligand for Notch receptors in stem cells (10). These facts indicate that JAG1 expression on progenitor cells induced by canonical WNT signaling activation leads to the maintenance of self-renewal potential of stem cells through Notch signaling activation (Fig. 3C).

Expression of human JAG1 mRNA was detected in ES cells, neural tissues, lung carcinoid, gastric cancer, pancreatic cancer, colon cancer, and also in SCC of skin, oral cavity, esophagus, as well as head and neck in this study. Because JAG1 functioning as WNT-dependent Notch signaling activator is the key molecule maintaining the homeostasis of stem and progenitor cells, JAG1 is a pharmacogenomics target in the fields of oncology and regenerative medicine.

\section{References}

1. Katoh M: WNT and FGF gene clusters (review). Int J Oncol 21: 1269-1273, 2002.

2. Robbins J, Blondel BJ, Gallahan D and Callahan R: Mouse mammary tumor gene int-3: a member of the Notch gene family transforms mammary epithelial cells. J Virol 66: 2594-2599, 1992.

3. Katoh M: Regulation of WNT signaling molecules by retinoic acid during neuronal differentiation in NT2 cells: threshold model of WNT action (review). Int J Mol Med 10: 683-687, 2002.

4. Heller RS, Klein T, Ling Z, Heimberg H, Katoh M, Madsen OD and Serup P: Expression of WNT, Frizzled, $s F R P$, and $D K K$ genes in adult human pancreas. Gene Expr 11: 141-147, 2003.

5. Garciadiego-Cazares D, Rosales C, Katoh M and ChimalMonroy J: Coordination of chondrocyte differentiation and joint formation by $\alpha 5 \beta 1$ integrin in the developing appendicular skeleton. Development 131: 4735-4742, 2004.

6. Swain RK, Katoh M, Medina A and Steinbeisser H: Xenopus frizzled-4S, a splicing variant of Xfz4, is a context-dependent activator and inhibitor of Wnt/ß-catenin signaling. Cell Commun Signal 3: 12, 2005.

7. Katoh M: WNT2B: comparative integromics and clinical application (review). Int J Mol Med 16: 1103-1108, 2005.

8. Katoh M: Epithelial-mesenchymal transition in gastric cancer (review). Int J Oncol 27: 1677-1683, 2005.

9. Artavanis-Tsakonas S, Rand MD and Lake RJ: Notch signaling: cell fate control and signal integration in development. Science 284: 770-776, 1999.

10. Radtke F and Raj K: The role of Notch in tumorigenesis: oncogene or tumor suppressor? Nat Rev Cancer 3: 765-767, 2003.

11. Katoh $\mathrm{M}$ and Katoh $\mathrm{M}: F G F R 2$ and WDR11 are neighboring oncogene and tumor suppressor gene on human chromosome 10q26. Int J Oncol 22: 1155-1159, 2003.

12. Eswarakumar VP, Lax I and Schlessinger J: Cellular signaling by fibroblast growth factor receptors. Cytokine Growth Factor Rev 16: 139-149, 2005.

13. Katoh $\mathrm{M}$ and Katoh $\mathrm{M}$ : Comparative genomics on FGF8, $F G F 17$, and FGF18 orthologs. Int J Mol Med 16: 493-496, 2005.

14. Katoh Y and Katoh M: Comparative genomics on FGF 16 orthologs. Int J Mol Med 16: 959-963, 2005.

15. Katoh $\mathrm{M}$ and Katoh M: Comparative genomics on FGF20 orthologs. Oncol Rep 14: 287-290, 2005.

16. Katoh Y and Katoh M: KIF27 is one of orthologs for Drosophila Costal-2. Int J Oncol 25: 1875-1880, 2004.

17. Katoh Y and Katoh M: Characterization of KIF7 gene in silico. Int J Oncol 25: 1881-1886, 2004.

18. Van den Brink GR, Bleuming SA, Hardwick JC, et al: Indian Hedgehog is an antagonist of Wnt signaling in colonic epithelial cell differentiation. Nat Genet 36: 277-282, 2004.

19. Hooper JF and Scott MP: Communicating with Hedgehogs. Nat Rev Mol Cell Biol 6: 306-317, 2005.

20. Katoh Y and Katoh M: Hedgehog signaling in gastric cancer. Cancer Biol Ther 4: 1050-1054, 2005.

21. Katoh Y and Katoh M: Identification and characterization of rat Desert hedgehog and Indian hedgehog genes in silico. Int $\mathbf{J}$ Oncol 26: 545-549, 2005.

22. Katoh Y and Katoh M: Identification and characterization of DISP3 gene in silico. Int J Oncol 26: 551-556, 2005.

23. Katoh Y and Katoh M: WNT antagonist, SFRP1, is Hedgehog signaling target. Int J Mol Med 17: 171-175, 2006.

24. Katoh Y and Katoh M: Comparative genomics on BMP4 orthologs. Int J Oncol 27: 581-585, 2005.

25. Gray GE, Mann RS, Mitsiadis E, et al: Human ligands of the Notch receptor. Am J Pathol 154: 785-794, 1999.

26. Bulman MP, Kusumi K, Frayling TM, et al: Mutations in the human delta homologue, DLL3, cause axial skeletal defects in spondylocostal dysostosis. Nat Genet 24: 438-441, 2000.

27. Shutter JR, Scully S, Fan W, et al: Dll4, a novel Notch ligand expressed in arterial endothelium. Genes Dev 14: 1313-1318, 2000.

28. Lindsell CE, Shawber CJ, Boulter J and Weinmaster G: Jagged: a mammalian ligand that activates Notch1. Cell 80: 909-917, 1995. 
29. Luo B, Aster JC, Hasserjian RP, Kuo F and Sklar J: Isolation and functional analysis of a cDNA for human Jagged2, a gene encoding a ligand for the Notch1 receptor. Mol Cell Biol 17: 6057-6067, 1997.

30. Ellisen LW, Bird J, West DC, et al: TAN-1, the human homolog of the Drosophila notch gene, is broken by chromosomal translocations in T lymphoblastic neoplasms. Cell 66: 649-661, 1991.

31. Larsson C, Lardelli M, White I and Lendahl U: The human NOTCH1, 2, and 3 genes are located at chromosome positions $9 \mathrm{q} 34,1 \mathrm{p} 13-\mathrm{p} 11$, and 19p13.2-p13.1 in regions of neoplasiaassociated translocation. Genomics 24: 253-258, 1994.

32. Joutel A, Corpechot C, Ducros A, et al: Notch3 mutations in CADASIL, a hereditary adult-onset condition causing stroke and dementia. Nature 383: 707-710, 1996.

33. Sugaya K, Sasanuma S, Nohata J, et al: Gene organization of human NOTCH4 and (CTG)n polymorphism in this human counterpart gene of mouse proto-oncogene Int3. Gene 189: 235-244, 1997.

34. Davis RL and Turner DL: Vertebrate hairy and enhancer of split related proteins: transcriptional repressors regulating cellular differentiation and embryonic patterning. Oncogene 20: 8342-8357, 2001.

35. Katoh $\mathbf{M}$ and Katoh $\mathrm{M}$ : Identification and characterization of human HES2, HES3, and HES5 genes in silico. Int J Oncol 25: 529-534, 2004.

36. Katoh $\mathrm{M}$ and Katoh $\mathrm{M}$ : Identification and characterization of human HESL, rat Hesl and rainbow trout hesl genes in silico. Int J Mol Med 14: 747-751, 2005

37. Katoh M: Paradigm shift in gene-finding method: from benchtop approach to desk-top approach. Int J Mol Med 10: 677-682, 2002.
38. Katoh $\mathbf{M}$ and Katoh $\mathbf{M}$ : Identification and characterization of human BCL9L gene and mouse Bcl9l gene in silico. Int J Mol Med 12: 643-649, 2003.

39. Katoh Y and Katoh M: Identification and characterization of rat Wnt6 and Wnt10a genes in silico. Int J Mol Med 15: 527-531, 2005.

40. Katoh Y and Katoh M: Comparative genomics on $D K K 1$ orthologs. Int J Oncol 27: 275-279, 2005.

41. Katoh Y and Katoh M: Comparative genomics on $D K K 2$ and DKK4 orthologs. Int J Mol Med 16: 477-481, 2005.

42. Katoh Y and Katoh M: Comparative genomics on SLIT1, SLIT2, and SLIT3 orthologs. Oncol Rep 14: 1351-1355, 2005.

43. Katoh Y and Katoh M: Identification and characterization of rat Wnt1 and Wnt10b genes in silico. Int J Oncol 26: 841-845, 2005.

44. Katoh $\mathrm{M}$ and Katoh M: Comparative genomics on WNT8A and WNT8B genes. Int J Oncol 26: 1129-1133, 2005.

45. Katoh M: Molecular evolution of $W N T 2 B$ orthologs. Int J Oncol 26: 1135-1139, 2005.

46. Katoh M: Comparative genomics on WNT3-WNT9B gene cluster. Int J Mol Med 15: 743-747, 2005.

47. Katoh $\mathrm{M}$ and Katoh M: Comparative genomics on WNT5A and WNT5B genes. Int J Mol Med 15: 749-753, 2005

48. Katoh Y and Katoh M: Comparative genomics on WNT11 gene. Int J Mol Med 15: 879-883, 2005.

49. Sander GR and Powell BC: Expression of Notch receptors and ligands in the adult gut. J Histochem Cytochem 52: 509-516, 2004. 